\title{
Sustentação pedagógica e legislação do ensino- aprendizagem: a formação em enfermagem no Brasil
}

\author{
Rosa Gomes dos Santos Ferreira \\ Escola de Enfermagem Anna Nery - UFRJ \\ Hospital Municipal Miguel Couto - SMS/RJ \\ $₫$ rosaipub@gmail.com \\ Jorge Luiz do Nascimento \\ Hospital Municipal Miguel Couto - SMS/RJ
}

Recebido em 13 de setembro de 2016

Aceito em 31 de maio de 2017

\section{Resumo:}

Produto final do curso da disciplina "Seminário sobre a problemática do ensino de enfermagem", ofertada pelo Programa de Pós-Graduação em Enfermagem da Universidade Federal do Rio de Janeiro, que teve como objetivos: Refletir a respeito da sustentação pedagógica, bases legais e inovações acerca do ensino de Enfermagem; semear ideias sobre o contexto da Educação em Enfermagem, com enfoques teóricos e educacionais; Analisar o desenvolvimento da Educação em Enfermagem no Brasil. Através da busca científica nas bases indexadas de dados LILACS, MEDLINE, PUBMED e SCIELO, bibliografia virtual e impressa de livros conceituais e legislação acerca do assunto, analisamos o tema, concluindo que Enfermagem tem fundamentado seu conhecimento em bases legais amadurecidas, por meio de longo período de discussão democrática, através da participação dos profissionais que executam a assistência e a docência, junto aos órgãos responsáveis pelo seu cumprimento. Contudo, as diretrizes representam a base norteadora no processo de construção curricular, cabendo às universidades, adequar à sua realidade, os projetos políticos e pedagógicos que serão assumidos, visto que a Lei permite essa autonomia. Ressalta-se a importância da participação e compromisso acadêmico de discentes, docentes e da população no processo das reformas curriculares, intentando a participação coletiva e a busca por uma assistência de enfermagem de qualidade.

Palavras-chave: Educação em enfermagem; Educação; Legislação; Educação em saúde.

\section{Pedagogical support and legislation of teaching-learning: nursing training in Brazil}

\begin{abstract}
:
Final product of the course the course "Seminar on the problems of nursing education", offered by the Program of Graduate Studies in Nursing at the Federal University of Rio de Janeiro, which aimed to: Reflect about the pedagogical concepts, legal bases and innovations about nursing education; Sow ideas on the education context in Nursing, with theoretical and educational approaches; Analyze the development of Nursing Education in Brazil. Through scientific search in indexed bases LILACS, MEDLINE, PUBMED and SCIELO, virtual bibliography and printed conceptual books and legislation on the subject, we analyzed the issue and concluded that nursing has built its expertise in legal bases matured through long of democratic discussion, through the participation of professionals who perform the care and teaching with the competent bodies and responsible for compliance. However, the guidelines represent only guiding based on the curriculum development process, leaving the universities, fit their reality, political and educational projects to be
\end{abstract}


undertaken, as the law allows this autonomy. It emphasizes the importance of participation and academic commitment to students, teachers and the public in the process of curriculum reform, attempting to collective participation and the pursuit of a quality nursing care.

Keywords: Education in nursing; Education; Law; Health education.

\section{Sustentación pedagógica y legislación de la enseñanza- aprendizaje: la formación en enfermería en Brasil}

\section{Resumen:}

El producto final del curso el curso "Seminario sobre los problemas de la educación de enfermería", ofrecido por el Programa de Estudios de Posgrado en Enfermería de la Universidad Federal de Río de Janeiro, que tiene por objeto: Reflexionar sobre los conceptos pedagógicos, bases legales y las innovaciones sobre la educación de enfermería; Sembrar ideas en el contexto de la educación en Enfermería, con los enfoques teóricos y educativos; Analizar el desarrollo de la Educación en Enfermería en Brasil. A través de la búsqueda científica en bases indexadas LILACS, MEDLINE, PubMed y SciELO, bibliografía virtual y libros impresos conceptuales y la legislación sobre la materia, se analizó el tema y concluimos que la enfermería ha construido su experiencia en bases jurídicas madurada durante mucho tiempo de la discusión democrática, a través de la participación de los profesionales que realizan el cuidado y la enseñanza con los organismos competentes y responsables de su cumplimiento. Sin embargo, las directrices sólo representan el guiado basan en el proceso de desarrollo curricular, dejando a las universidades, adaptarse a su realidad, política y proyectos educativos que se realizarán, como la ley permite que esta autonomía. Se hace hincapié en la importancia de la participación y el compromiso académico a los estudiantes, maestros y el público en el proceso de reforma curricular, tratando de participación colectiva y la búsqueda de una atención de enfermería de calidad.

Palabras clave: Educación in enfermería; Educación; Derecho; Educación para la salud.

\section{INTRODUÇÃO}

O artigo em tela é fruto do curso da disciplina "Seminário sobre a problemática do ensino de enfermagem", ofertada pelo Programa de Pós-Graduação em Enfermagem da Universidade Federal do Rio de Janeiro, Escola de Enfermagem Anna Nery, em nível de mestrado e doutorado em enfermagem.

Esta disciplina abarca discussões a respeito dos entraves e questões associadas ao processo crítico-reflexivo que permeiam o ensino-aprendizagem em Enfermagem e o contexto da educação em enfermagem no Brasil: concepções pedagógicas, bases legais, inovações no processo de ensino-aprendizagem, sendo a temática escolhida para análise.

Os objetivos elencados para a discussão:

- Refletir a respeito das concepções pedagógicas, bases legais e inovações acerca do ensino de Enfermagem; 
- Semear idéias sobre o contexto da Educação em Enfermagem no Brasil, com enfoques teóricos e educacionais;

- Analisar o desenvolvimento da Educação em Enfermagem no Brasil.

Cabe-nos compreender a avaliar a educação em enfermagem, como algo processual, contínuo e que delineia o perfil profissional solicitado pelo contexto sócio histórico em que nos encontramos.

O ensino e aprendizado em enfermagem é caracterizado por intensos desafios, seja no campo da academia, seja no âmbito das instituições do cotiano da prática profissional, dada as constantes modificações e exigências que tangenciam o processo. (WALDOW, 2009)

Justificamos a apresentação desta matéria, dada a preocupação a respeito do arcabouço dos processos de ensinar e aprender em enfermagem, com vista à qualificação dos processos formativos contínuos e do trabalho com vistas às demandas sociais.

\section{METODOLOGIA}

A pesquisa qualitativa se volta à análise dos significados que os próprios sujeitos atribuem às suas ações, no meio social em que acontecem as relações, isto é, estuda os vínculos indissociáveis das ações individuais com o contexto social, no qual este indivíduo está inserido (CHIZZOTTI, 2001).

Através da busca nas bases indexadas de dados LILACS, MEDLINE, PUBMED e SCIELO e consulta à bibliografia virtual e impressa de livros conceituais e legislação acerca do assunto, viabilizamos uma forma de analisar criteriosamente o tema abordado.

Iniciamos a pesquisa com a identificação das fontes documentais com posterior análise e levantamento das informações para reconhecimento das idéias sobre o objeto de estudo.

A busca foi realizada tomando-se por base os Descritores em Ciências da Saúde da Biblioteca Virtual em Saúde. São eles: educação em enfermagem, educação, legislação. 
Adotamos como recorte temporal, o produzido na temporalidade dos últimos dez anos (2010-2017), no idioma português. Analisamos, adotando como critérios de inclusão, as produções referentes aos textos completos, não contemplando a leitura publicada sob os demais formatos.

Após a identificação do conteúdo constante nas bases de dados, dados, refinamos as buscas, abarcando conceitos extraídos de documentos e legislações pertinentes ao assunto, bem como à bibliografia apresentada sob o formato de livros.

Além disto, trouxemos o assunto em tela, para o ambiente da sala de aula, no curso da disciplina eletiva referida, sob a modelagem de seminário.

Severino (2007, p.95) afirma que nos seminários podem ser "escalados previamente, onde alguns debatedores recebem o texto com antecedência e são chamados a se pronunciar formalmente a respeito dos problemas".

A repercussão do seminário consiste na "capacidade de pesquisa, análise, de interpretação e de síntese dos alunos, por meio tanto do exercício da oralidade quanto da sistematização escrita de sua reflexão [...] fortalece e amplia as formas de interação do aluno com o saber, com seus colegas e com o professor". (FARIAS, 2009, p.140)

Um aspecto central na concepção de avaliação formativa (Zukowsky-Tavares, 2012) é a garantia do espaço de autonomia do estudante, tornando-o cada vez mais sujeito da aprendizagem, por meio de reflexões individuais e conjuntas, analisando criticamente sua produção e tendo em vista a transformação da sua realidade pessoal e social.

Adicionando os elementos descritos, subsidiados por estratégicas intervenções de nosso professor orientador, institui-se rico debate.

\section{CONSIDERAÇõES TEÓRICAS}

\section{Considerações sobre a educação no Brasil}

A pedagogia tradicional, onde o enfoque era o ensino professor-centrado, vem dando lugar às novas práticas, oriundas de novas propostas e novos objetivos comportamentais, 
onde o ator principal é o aluno. (WALDOW, 2009)

Prioritariamente, busca-se por uma tipologia de ensino de qualidade e contributivo com o processo de ensinar e de aprender, o foco de alcance das sociedades atuais. (SCHWINGEL et al, 2016)

A educação de nível superior no Brasil passou por um modelo disciplinar, fragmentado, composto por disciplinas obrigatórias e eletivas, regulamentada pela Lei Federal nº. 5.540, de 28/11/1968 (Lei de Diretrizes e Bases para Educação Superior).

O currículo mínimo era adotado de grade de conteúdos computados, desvinculados entre si; fragmentados e desarticulados entre a área básica e clínica, induzindo à especialização, dissociado do sistema de saúde4. Este modelo vigorou até a aprovação da atual Lei de Diretrizes e Bases da Educação Nacional (LDB), Lei Federal nº. 9.394, de 20/12/1996 (BRASIL, 1996).

As diretrizes produziram atribuições inovadoras às Instituições de Ensino Superior (IES), aos docentes, aos discentes e até mesmo à população, no sentido de proporcionar a construção do conhecimento a partir do perfil de cada escola e da comunidade em que está inserida. A LDB estabelece que a educação escolar deva vincular-se ao trabalho e à prática social, destacando o desenvolvimento do educando, seu preparo para o exercício da cidadania e a qualificação para o trabalho (GALLEGUILLOS e OLIVEIRA, 2001).

A educação no Brasil para Silva et al., (2012) é então construída sob um novo paradigma: a formação por competências, entendida como um processo contínuo e a efetiva participação do educando e todos os envolvidos no processo ensino-aprendizagem.

Para entendermos como sobrevieram essas transformações na educação no Brasil, que induziram à edificação da Lei de Diretrizes e Bases da Educação Nacional, destacamos a Conferência Internacional de Educação, em 1990, na Tailândia, patrocinada pela UNESCO, quando foi elaborada a Declaração Mundial sobre Educação para Todos.

Essa conferência resultou em um relatório escrito por Jacques Delors, entre 1993 e 1996, e traz como eixo estrutural básico que: "A educação deve organizar-se em torno de quatro aprendizagens que, ao longo da vida, serão de algum modo, para cada indivíduo, os pilares do conhecimento: aprender a conhecer, aprender a fazer, aprender a viver juntos, aprender a ser" (DELORS, 2003). 
Esses quatro pilares são adotados como base para o processo de ensino aprendizagem. Abaixo, o significado de cada um deles:

Aprender a conhecer: Prioriza-se o domínio dos instrumentos do conhecimento, considerando como meio e fim. Meio, enquanto forma de conhecer a complexidade do mundo, condição necessária para viver dignamente, desenvolver possibilidades pessoais e profissionais, para se comunicar. Fim, porque seu fundamento é o prazer de compreender, de conhecer, de descobrir.

Com isto, desenvolve-se a curiosidade intelectual, estimula-se o senso crítico e permite-se compreender o real, mediante a aquisição da autonomia na capacidade de discernir, favorecendo as bases para continuar aprendendo ao longo da vida.

Aprender a fazer: O desenvolvimento das habilidades e o estímulo ao surgimento de aptidões tornam-se essenciais, na medida em que se criam qualidades necessárias para o enfrentamento de situações cotidianas.

Aprender a viver: Aprender a viver juntos, desenvolvendo o conhecimento do outro e a percepção das interdependências, de modo a permitir a realização de projetos comuns ou a gestão dos conflitos.

Aprender a ser: A educação deve estar comprometida com o desenvolvimento total da pessoa. Supõem a preparação do indivíduo para formar pensamentos autônomos e críticos, seus juízos de valor.

Ensinar e aprender sustentados base nos pilares da educação vincula o professor enfermeiro a participar de um processo contínuo de desenvolvimento de competências e habilidades para ensinar Enfermagem, atualizando seus conhecimentos, nomeando uma prática pedagógica conexa para que os discentes adquiram autonomia e pensamento crítico reflexivo para a vida e trabalho.

Sob esta concepção, surge a idéia de que "o exercício e o treino poderiam bastar para sustentar competências essenciais, se a escola fosse um mundo estável" e como isto não acontece na realidade, uma vez que todos trabalham em "contextos inéditos, diante de públicos que modificam em referência a programas repensados, supostamente baseados em novos paradigmas", torna-se evidente que "os recursos cognitivos mobilizados pelas competências devem ser atualizados, adaptados às condições de trabalho em evolução" (PERRENOUD, 2002). 
A literatura corrente sobre a noção de competência aponta que esta é a capacidade de articular e mobilizar conhecimentos, habilidades e atitudes, colocando-os em ação para deliberar problemas e enfrentar situações de imprevisibilidade em uma dada situação concreta de trabalho e em um determinado contexto cultural (PERRENOUD, 1999).

Em se tratando de educação para o mundo do trabalho, o processo ensinoaprendizagem deve favorecer a troca de informações entre professores e alunos, trabalhando a partir de situações-problema, buscando soluções para um contexto de atuação profissional em constante mudança.

Segundo a LDB, conforme o Art. $3^{\circ}$, o ensino será ministrado com base nos princípios da igualdade de acesso e permanência na escola, da liberdade de aprender, ensinar, pesquisar, do pluralismo de idéias e de concepções pedagógicas, do respeito à liberdade e tolerância, da gestão democrática do ensino público, da valorização da experiência extraescolar, da vinculação entre educação escolar, o trabalho e as práticas sociais.

A discussão da educação e da relação pedagógica só é possível se situarmos estas, como prática social (MS, 2013) e isto não pode ser visto como atividade que se exprime como fenômeno ou fato, mas todo um conjunto de atividades humanas que se particularizam de qualquer conduta "natural".

É oportuno registrar que nenhuma prática, justamente por ser humana, pode prescindir de elementos teóricos e que incorpora uma reflexão sobre o mundo, sobre a vida, sobre si mesma, enquanto parte constitutiva indispensável da humanidade.

O padrão de currículo atual deve agenciar o desenvolvimento de competências, despertando a visão crítico-reflexiva da atuação do cidadão na sociedade. Além disso, o currículo proposto no Projeto Político Pedagógico deve apadrinhar o intercâmbio entre teoria e prática contextualizadas com a realidade em que o educando irá vivenciar.

Portanto, considera-se que, na pedagogia, a visão da liberdade deve assumir importância fundamental e a assinalar como sendo a matriz que confere sentido a uma prática educativa que só pode impetrar efetivamente, na medida da participação livre e crítica dos educandos. (FREIRE, 1975). 


\section{Considerações sobre a Educação em Enfermagem no Brasil}

A reestruturação das Diretrizes Curriculares para a área da saúde apresentou considerações incentivadoras sobre a prática educativa estar aliada à prática assistencial e coletiva. Apesar da implantação das Diretrizes que vigoram atualmente terem ocorrido há mais de dez anos atrás, a discussão que embasa seus textos é bem atual demonstrando desde então uma preocupação com a formação dos profissionais da saúde e o quão desafiador ainda esse caminho se apresenta diante das adversidades e pluralidades em que vivemos (SILVA e SANTANA, 2007)

Para a construção das novas diretrizes curriculares, o MEC convocou publicamente as instituições de ensino superior e as associações profissionais para participarem desse processo. Diante disso, a ABEn foi responsável por realizar encontros freqüentes de discussão e elaboração das diretrizes gerais da educação em enfermagem. Dentre eles, destacam-se os Seminários Nacionais de Diretrizes para a Educação em enfermagem (SENADEn), criados com a finalidade de analisar a educação em enfermagem e seus diferentes níveis de atenção e articulando os diversos níveis de formação. Em especial, citamos o 30. SENADEn que tinha o propósito específico de discutir a LDB e que gerou documentos que serviram de base para as novas diretrizes curriculares (GALLEGUILLOS e OLIVEIRA, 2001)

As Diretrizes Curriculares Nacionais do curso de Enfermagem (DCN/ENF) foram elaboradas por meio de uma construção coletiva e constituem orientações para a elaboração de currículos de graduação em enfermagem. A proposta aprovada pelo Conselho Nacional de Educação, através da Resolução CNE/CES no. 3 de 2001, foi fruto de debates nacionais com a participação de profissionais da área, das Secretarias de Educação do Ensino Superior e da Saúde, das Instituições de Ensino Superior, da ABEn, da categoria profissional dos enfermeiros e dos estudantes (REBOUÇAS, 2013)

As diretrizes possuem como objetivos essenciais direcionar os alunos dos cursos de graduação a exercitar o aprendizado em aprender, permitindo a qualificação de profissionais preparados para a reflexão, a crítica, a reconstrução e a execução (ME, 2001)

A partir dessa Resolução houve a construção de novos projetos pedagógicos em diversas instituições de ensino. Essas transformações foram sustentadas pelos conteúdos norteadores contidos nas diretrizes. Passou-se a primar pela excelência na formação do 
enfermeiro através dos eixos principais contidos nas DNC/ENF, alguns descritos aqui: formação integral, incentivo e incorporação de metodologias ativas, atividades que reforcem a educação, flexibilização da sistematização dos cursos, conteúdos mínimos necessários para uma boa formação profissional assegurados, articulação entre o ensino teórico e a prática assistencial e a indissociabilidade entre os pilares ensino, pesquisa e extensão (REBOUÇAS, 2013)

A DCN/ENF possibilitou uma transformação paradigmática, pois mesmo antes de sua implantação, sua composição foi pautada na democracia através de conferências entre as partes e os profissionais que possuíam as mesmas inquietudes: discutir o sistema educacional na área visando a melhor qualidade do ensino e da prática assistencial. Sua elaboração objetivou, acima de tudo, a flexibilização do ensino e da grade curricular visando suplantar o antigo currículo mínimo e pautar na formação de enfermeiros competentes, analíticos e envolvidos com a saúde da população além da participação discente mais ativa e reflexiva. Ademais, as Instituições de Ensino Superior passaram a assumir novas posturas e responsabilidades no processo de formação profissional pautadas na autonomia didáticocientífica para a criação de projetos pedagógicos (REBOUÇAS, 2013)

O enfermeiro passa a ser definido como um profissional que necessita de uma formação acadêmica generalista, que englobe conceitos de humanização, capacitação técnica e científica, com visão crítica e reflexiva e com competência para exercer a profissão em todos os níveis de atenção sob os princípios da ética. A assistência de enfermagem deve estar direcionada às peculiaridades da população, voltando-se para os processos saúde/doença predominantes. Desse modo, visando a adequação do currículo às exigências da prática assistencial, a reforma curricular dos cursos de graduação em enfermagem, foi embasada nos princípios da solidariedade, cidadania e dos pilares da educação (BISCARDE et al., 2014)

\section{Considerações sobre a Extensão e a Pesquisa em Enfermagem}

As DCN/ENF proporcionaram avanços não somente na área assistencial e curricular para a enfermagem, pois como uma das propostas foi a indissociabilidade entre educação pesquisa e extensão, conseqüentemente, as áreas de produção do conhecimento (pesquisa) e de aproximação do conhecimento com a população (extensão) também obteve crescimento 
considerável em relação ao período anterior à Resolução. A evolução dos programas de pósgraduação no Brasil trouxe consigo um acréscimo substancial nas publicações em enfermagem. (ERDMANN e LANZONI, 2008)

A produção científica em enfermagem multiplica-se à medida que a pós-graduação se expande. Entretanto, ao compararmos os meios de divulgação mais utilizados na área, nota-se que as publicações em simpósios e congressos são os meios em que há maior expressividade em relação aos periódicos. Logo, a dificuldade encontrada na expansão do conhecimento traduzida pela sua velocidade lentificada e propagada no campo da saúde por parte dos enfermeiros, pode ser causada devido aos canais escolhidos por eles. (ERDMANN e LANZONI, 2008)

Apesar do aumento do número de produção e de atividades extensionistas no meio acadêmico, estudos apontam que, no campo da enfermagem, os grupos de pesquisa ainda se organizam de maneira embrionária, ou seja, as estratégias utilizadas para a pesquisa e extensão ainda são insuficientes para o desenvolvimento efetivo da assosciação que as diretrizes preconizam. Devido a isso, faz-se mister o empenho na elaboração e divulgação dos conhecimentos produzidos na área da enfermagem (ERDMANN e LANZONI, 2008).

Em contrapartida, o ensino associado à pesquisa e às atividades de extensão, favorece a aproximação entre a universidade e a comunidade, pois abre caminhos para o crescimento profissional dos acadêmicos enquanto trocam experiências e conhecimentos com a sociedade ao qual fazem parte (COSTA e CARVALHO, 2001).

A ligação entre essas três bases (educação, pesquisa e extensão), além de trazer contribuições para a formação acadêmica através de novos conhecimentos, permite ao discente a coparticipação em seu processo de ensino-aprendizado.

\section{DISCUSSÃo}

Apesar dos avanços obtidos na formação acadêmica, algumas dificuldades permeiam a implantação das diretrizes curriculares no campo da enfermagem. Uma delas, segundo Silva e Freitas, é representada pelo quantitativo de profissionais capacitados responsáveis 
pela avaliação dos cursos de graduação ser insuficiente ao número de escolas de enfermagem, cujo desregrado crescimento têm sido pauta de discussões acerca da atual capacitação profissional. Outro fator que dificulta a execução das diretrizes é a distância entre a teoria e a prática ainda se faz muito presente. A interligação entre o ensino e a assistência prestada é condição essencial para a efetivação do processo de aprendizagem do graduando (SILVA e FREITAS, 2012).

Devido à expansão desordenada dos cursos de graduação em enfermagem visualizada, especialmente no setor privado, nota-se uma descontinuidade dos avanços em relação à implementação das diretrizes. Conseqüentemente, a formação do profissional de enfermagem e da saúde já dá sinais de estagnação nas reformas curriculares e na estruturação de projetos pedagógicos que contemplem o preparo do profissional generalista crítico e reflexivo pautado na consciência da coletividade e preocupado com as políticas públicas de saúde (SILVA, 2012).

Com o advento das inovações tecnológicas e avanços nos meios de comunicação e desenvolvimento social, os dilemas éticos passam a representar um peso com consequências por vezes decisivas para o profissional de enfermagem.

A questão ética retrata mais uma dificuldade dentro da formação do enfermeiro. Essas questões sempre estiveram presentes na área da saúde, entretanto, nunca foram tão evidenciadas e divulgadas como na atualidade (MARCO et al., 2013).

O currículo de uma instituição deve ser desenvolvido a partir da vivência dos seus discentes e docentes, com base em conteúdos abordados de forma dinâmica e flexível. Assim, a estruturação dos currículos ocorre de maneira integrada, em que as disciplinas interagem entre si, umas corroborando com as outras e possibilitando o raciocínio crítico e reflexivo dos graduandos. Parte-se da premissa que professores não são detentores do saber, mas que o conhecimento é construído em conjunto. Logo, o currículo deveria estar caracterizado pela realidade vivenciada e reconhecida pelos indivíduos que habitam as escolas (SILVA e FREITAS, 2011)

A despeito das DCN/ENF apresentarem, inquestionavelmente, avanços na estruturação do saber em enfermagem, não se pode atribuí-las única e exclusivamente ao processo de mudança da formação em enfermagem. Vale destacar a participação docente e seu comprometimento com a educação, a dedicação dos enfermeiros durante a assistência e 
a constante preocupação com a qualidade do serviço, atrelados ao dever social e político da enfermagem e a importância das políticas públicas de saúde e educação.

Portanto, o projeto político pedagógico, para ser desenvolvido de forma integrada com as necessidades de saúde da sociedade, deve estar alicerçado nas atuais diretrizes curriculares. Deve buscar, acima de tudo, explorar os conhecimentos advindos da prática em consonância com os adquiridos cientificamente através de construtos teóricos, com ênfase no SUS e na construção coletiva. A formação profissional não pode se ater aos conteúdos mínimos e limitados, porém, deve garantir a liberdade na construção do aprendizado sem restrições, mas com discernimento, alicerçado no trabalho em equipe e na capacitação com consciência e ética. Assim, teremos enfermeiros capazes de cuidar do próximo com qualidade, humanização e integralidade da assistência.

\section{CONSIDERAÇÕES FINAIS}

O contexto da educação em enfermagem no Brasil é representado por transformações essenciais para a consolidação do processo ensino-aprendizagem na formação profissional. As concepções pedagógicas e bases legais que permeiam a Enfermagem ratificam a preocupação docente e profissional com a educação e com a assistência prática.

Ao longo desses dez anos das novas DCN/ENF, a construção coletiva do ensino em detrimento da postura anterior no método hierarquizado e individualizado de formação, proporcionou um crescimento significativo na disseminação do conhecimento em Enfermagem. Todavia, ainda persistem comportamentos profissionais e políticos que carecem da visão social com participação comunitária, tanto por parte de profissionais da prática quanto por parte das políticas públicas e projetos pedagógicos.

A reforma curricular vem sendo consolidada nos cursos de graduação de forma lenta e gradativa, por vezes em velocidade menor que os avanços tecnológicos e de comunicação, favorecendo o surgimento de lacunas no processo ensino-aprendizagem. Além disso, o número crescente da criação de novos cursos de graduação ocorrendo de forma desordenada, associado ao pequeno contingente profissional responsável por fiscalizar os 
currículos e projetos pedagógicos assumidos nessas instituições, dificulta sobremaneira na consolidação efetiva das diretrizes em todas as instâncias.

Em contrapartida, as diretrizes curriculares são responsáveis por embasar o ensino em enfermagem e, por isso, os profissionais envolvidos com essa prática devem direcionar seus esforços para a concretização do aprendizado de qualidade e voltado para as questões públicas de saúde. Visando a melhoria da assistência dispensada à população, há que se priorizar as questões sociais em detrimento das individuais, a formação generalista em lugar de focar a especialidade, no ensino ético, crítico e reflexivo sobreposto ao fragmentado, desarticulado e verticalizado.

Conclui-se que a Enfermagem tem edificado sua área de conhecimento em bases legais amadurecidas por meio de um longo período de discussão organizada democraticamente e de maneira coletiva, através da participação dos próprios profissionais que executam a assistência e a docência junto aos órgãos competentes e responsáveis pelo seu cumprimento. Contudo, as diretrizes representam somente uma base norteadora no processo de construção curricular, pois cabe às universidades e instituições de ensino, adequar à sua realidade, os projetos políticos e pedagógicos que serão assumidos na educação, visto que a Lei permite essa autonomia por parte dos cursos. Desse modo, ressalta-se a importância da participação e compromisso acadêmico de discentes, docentes e da população no processo das reformas curriculares, intentando a participação coletiva e a busca por uma assistência de enfermagem de qualidade.

\section{REFERÊNCIAS}

BISCARDE, D.G dos S; PEREIRA-SANTOS, M; SILVA, L.B. Formação em saúde, extensão universitária e Sistema Único de Saúde (SUS): conexões necessárias entre conhecimento e intervenção centradas na realidade e repercussões no processo formativo. Interface (Botucatu), Botucatu, v. 18, n. 48, p. 177-186, 2014. Disponível em: $\leq$ http://www.scielo.br/scielo.php?script=sci arttext\&pid=S141432832014000100177\&lng=en\&nrm=iso>. Acesso em 03 Set. 2015.

BRASIL. Ministério da Educação. Lei das Diretrizes e Bases da Educação Nacional no. 9.394/96 de 20 de dezembro de 1996. Publicada Diário Oficial da União em 23/12/96, seção1. [s.1: s.n.], 1996. 
CHIZZOTTI, A.A. Pesquisa em ciências humanas e sociais. 5ª Ed. São Paulo: Cortez, 2001.p.77-104

DELORS, J; AL-MUFTI, I; AMAGI, I; CARNEIRO, R; CHUNG,F; GEREMEK,B; SAVANÉ, MA. Educação um tesouro a descobrir: Relatório para a UNESCO da Comissão Internacional sobre Educação para o Século XXI. $8^{\mathrm{a}}$ ed. São Paulo: Cortez, Brasília DF: MEC: UNESCO, 2003.

ERDMANN, A.L; LANZONI, G.M.deM. Características dos grupos de pesquisa da enfermagem brasileira certificados pelo CNPq de 2005 a 2007.Esc. Anna Nery, Rio de Janeiro, v. 12, n. 2, p. 316-322, junho 2008.Disponível em<http://www.scielo.br/scielo.php?script=sci arttext\&pid=S1414-

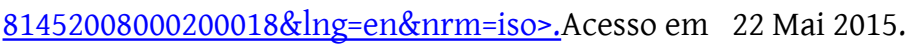

FREIRE, P. Educação como prática de liberdade. 5. Ed. Rio de Janeiro: Paz e Terra, 1975.

GALLEGUILLOS, T.G.B.; OLIVEIRA, M.A.C. A gênese e o desenvolvimento histórico do ensino de enfermagem no Brasil. Rev Esc Enf USP, v.35, n. 1,p. 80-7, mar. 2001.

MARCO, M.A.De; DEGIOVANI, M.V; TOROSSIAN, M.S, WECHSLER; R, JOPPERT; SILVIA, M.H; LUCCHESE, A.C. Comunicação, humanidades e humanização: a educação técnica, ética, estética e emocional do estudante e do profissional de saúde. Interface (Botucatu) [Internet]. 2013 Sep [cited 2016 Nov 07]; 17(46):683-693.Disponível em: http://www.scielo.br/scielo.php?script=sci arttext\&pid=\$141432832013000300015\&lng=en. Epub Aug 23, 2013.

PERRENOUD, P. Ascompetências para ensinar no século XXI: a formação dos professores e o desafio da avaliação. Porto Alegre: Artmed, 2002.

PERRENOUD, P. Construir as competências desde a escola.Porto Alegre: Artmed, 1999. 90p.

SCHWINGEL, T.C.P.G; ARAÚJO, M. C.P.; BOFF, E.T.O. A educação em saúde nos currículos de formação de professores. R. Transmutare, Curitiba, v. 1, n. 1, p. 126-140, jan./jun. 2016.

SILVA, M.J; SOUSA, E.M, FREITAS, C.L. Formação em enfermagem: interface entre as diretrizes curriculares e os conteúdos de atenção básica. Rev Bras Enferm, Brasília 2011 mar-abr; 64(2): 315-21.

SILVA, V.O; SANTANA, P.M.M.A. Curriculum content and Brazilian Health System (SUS): analytical categories, gaps and challenges. Interface (Botucatu). http://www.scielosp.org/pdf/icse/v19n52/1807-5762-icse-1807576220140017.pdf. Acesso em 13 set 2015.

TEIXEIRA, C.F.deS.; COELHO, M.T.Á.D; ROCHA, M.N.D. Bacharelado interdisciplinar: uma proposta inovadora na educação superior em saúde no Brasil. Ciênc. saúde coletiva, Rio deJaneiro , v. 18, n. 6, p. 1635-1646, June 2013 .Disponível em <http://www.scielo.br/scielo.php? script=sci_arttext\&pid=S14181232013000600015\&lng=en\&nrm=iso>. Acesso em 03 set. 2015.

ZUKOWSKY-TAVARES, C. Avaliação formativa da aprendizagem no ensino superior e o compromisso dos docentes e dos gestores. In: MASETTO, M.T. Inovação no ensino superior. São Paulo: Edições Loyola, 2012.

WALDOW, V. Reflexões sobre educação em enfermagem: enfase em um ensino centrado no cuidado. $O$ Mundo da Saúde São Paulo: 2009;33(2):182-188. 